\title{
State and Federal BRT Project Development Procedures: Managing Differences and Project Implementation Delays
}

\author{
Mark A. Miller
}

\begin{abstract}
Implementing a Bus Rapid Transit (BRT) system that is on a State Highway System and is part of the federal New Starts Project Planning and Development Program brings together two traditionally-separate types of transportation implementation projects: the traditional highway construction project and a public transportation project. The project development procedures (PDPs) for each of these types of projects-both of which must at times be followed-sometimes differ and can result in conflicts arising, can contribute to the use of resources that might not otherwise be used, and can create project implementation delays. An investigation was conducted of site-specific BRT projects, initially focusing on California and then extending nationwide, which led to the development of recommendations that, when put into practice, can help BRT project implementers mitigate the impact of having to follow multiple sets of PDPs and help implement the project more efficiently.
\end{abstract}

\section{Project Development Procedures for Bus Rapid Transit}

Running ways are the key element of Bus Rapid Transit (BRT) systems around which other BRT components (stations, vehicles, fare collection, service patterns, and identity and branding) revolve because running ways serve as the infrastructural foundation on which these other elements are based. Moreover, it is the running 
ways that allow for rapid and reliable movement of buses with minimal traffic interference to provide a definite sense of presence and permanence for BRT. BRT vehicles can operate on various types of running ways such as arterial streets, freeway lanes, and busways. Arterial streets include mixed traffic flow, a median bus lane, a curb bus lane, and a contraflow bus lane. Freeway lanes include reserved concurrent and contraflow lanes and bus-only lanes. Busways include tunnels as well as at-grade or grade-separated running ways (Levinson et al. 2003; Diaz and Hinebaugh 2009; Kittelson \& Associates, Inc., et al. 2007).

When BRT is implemented on arterial streets or freeway lanes, such running ways may also be part of a State Highway System (SHS). In such a setting, two customarily-distinct types of transportation implementation projects-a traditional State highway construction project and a public transportation project-converge in a single undertaking. This situation becomes even more complex if the BRT system is also part of the federal New Starts Project Planning and Development Program. The added complexity derives from the fact that two sets of sometimes differing Project Development Procedures (PDPs) - State or highway-based and federal or transit-based-may both have to be observed and, because of such differences in the PDPs, conflicts can arise and contribute to the use of resources that might not otherwise be used, and may also create implementation delays.

This paper presents an assessment of implementation delay for BRT systems resulting from having to follow either or both State-based and federally-based PDPs and is organized as follows: First, the methodology used in analyzing the differences between State-based and federally-based PDPs and the occurrence of project implementation delay is discussed. This is followed by an analysis and findings of a site-specific analysis of implementation delay and a discussion of recommendations developed to help mitigate the issues and implementation delays associated with having to follow both sets of PDPs. Last, conclusions and next steps for followon research are presented.

\section{Methodology}

\section{Reviewing the Literature for Project Development Procedures}

To investigate both State and federal PDPs used to implement BRT systems, pertinent documents dealing with both federal and State PDPs were reviewed, the latter focusing on California at the request of the California Department of Transportation (Caltrans), the sponsor of this research. For California PDPs, we reviewed the California PDP Manual (Caltrans 2009); a Caltrans booklet entitled “How Caltrans 
Builds Projects," which provides an overview of the Caltrans project delivery process (Caltrans 2011); and an online PDP tutorial available at www.dot.ca.gov/hq/ oppd/pdp/index.htm, developed by the Caltrans Division of Design, Office of Project Development Procedures. "How Caltrans Builds Projects" and the online tutorial are simplified versions of the complete and lengthy PDP Manual. To understand the set of procedures for the construction of a transit project-in particular, a BRT project-when federal funding has been applied for and/or approved under the Federal Transit Administration's (FTA's) New Starts Project Planning and Development Program, we examined numerous capital transit investment fact sheets that deal with different stages of project development, including Alternatives Analysis, Preliminary Engineering, and Final Design, and that also deal with Small Starts and Very Small Starts (Federal Transit Administration 2011). Studies by Levinson et al. (2003), Diaz and Hinebaugh (2009), and Kittelson \& Associates, Inc., et al. (2007) also assisted in understanding the BRT project development process with, respectively, planning and implementation guidelines for BRT, a reference tool that provides information on BRT systems including its seven major elements together with their respective features and attributes, and information on the costs, impacts, and effectiveness of implementing BRT.

\section{Comparing Transit- and Highway-Based PDPs}

After reviewing the PDP literature, we arranged side-by-side the stepwise flowcharts that Caltrans and FTA produced to describe the process of developing California-based highway projects and transit projects, respectively, as shown in Table 1. Each step within each PDP flow-chart, whether functionally simple or complex, was individually identified by either Caltrans or FTA as sufficiently important to have been included in their respective PDP. Accordingly, we maintained these flowcharts unchanged. The side-by-side nature of the flowcharts facilitated their comparison in order to more readily note similarities and differences. 


\section{Table 1. Stepwise Flowcharts for California (Highway-Based) and Federal (Transit-Based) Project Development Procedures}

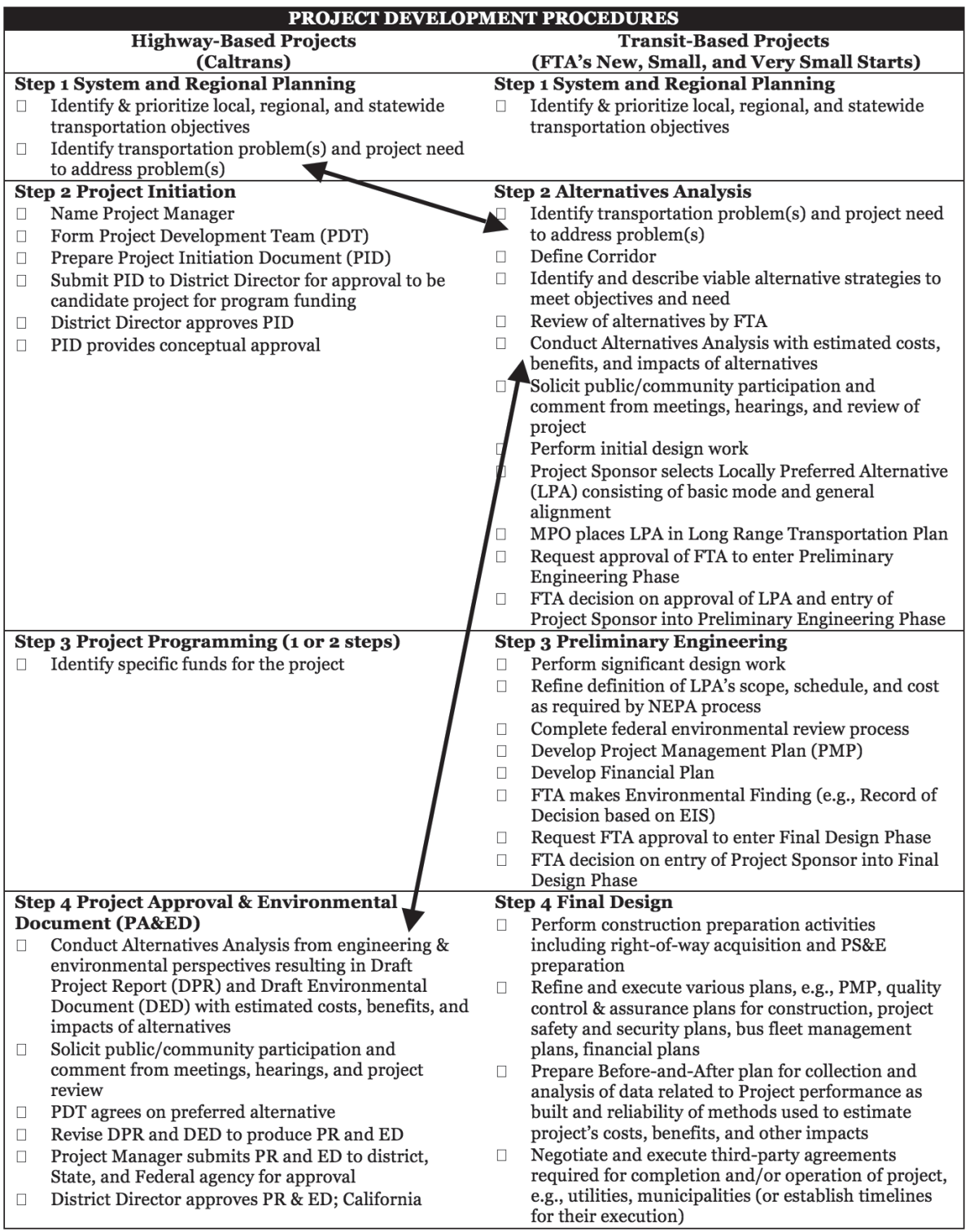




\section{PROJECT DEVELOPMENT PROCEDURES}

Transportation Commission adopts ED (CEQA); FHWA approves ED (NEPA)

$\square$ Update Project cost, scope, and schedule based on Preferred Alternative

Coordinate required environmental permits to ensure timely issuance when needed

Secure/commit all non-New Starts funding

$\square$ Evaluate (FTA) project for Full Funding Grant Agreement (FFGA)

Negotiate (FTA and Project Sponsor) terms and conditions for FFGA award to undertake project construction

\section{Step 5 Detailed Design}

$\square \quad$ Prepare fully developed Plans, Specifications, and Estimates (PS\&E), including utility relocation, traffic operations, and transportation management plans during construction. PS\&E includes details needed for bidding and building the project

- Acquire required $\mathrm{R} / \mathrm{W}$ that consider potential relocation impact studies (already completed and included in ED, airspace lease areas, $\mathrm{R} / \mathrm{W}$ cost data Obtain approvals, agreements, and permits as necessary and required

- Finalize PS\&E based on District-wide safety and constructability review

\section{Step 6 Construction}

$\square$ Award construction contract (prepare contract documents and bid package, advertise project to solicit bids, bids submitted and evaluated, construction contract awarded)

$\square$ Obtain expenditure authorization to begin construction

$\square \quad$ Assign Resident Engineer (RE) to administer contract

Contractor carries out construction activities Contractor finishes tasks on to-do list

Resolution of any contract disputes between contractor and RE

Contractor receives final project payment RE and PDT archive project documents

\section{Assessing Project Implementation Delays}

We examined the specific PDPs used by BRT projects both within and outside California by conducting site-specific assessments of these projects. Initially, we identified 12 applicable BRT projects in California and initial points of contact based on input from this study's Project Advisory Group. Final and appropriate points of contact at the relevant implementing agencies were subsequently identified, contacted, and interviewed by phone. Areas of the state with BRT projects that were investigated include:

- Sacramento metropolitan area (2 projects)

- San Francisco Bay Area (4 projects)

- San Diego metropolitan area (4 projects)

- Los Angeles metropolitan area (1 project)

- Monterey-San Luis Obispo area (1 project) 
For BRT projects outside California, initially, we focused on identifying projects that have either applied for and/or already received federal funding through FTA's New Starts Program. We reviewed each annual report on New Starts ranging from FY 2012 back through FY 2000, each of which contain a list of the projects recommended for funding in the President's budget for that specific year (Federal Transit Administration 2011). Many of the recent reports (2004 and later) include a "project profile" that identified the project sponsor and a project description. In some cases, Google Maps was used, which helped to accurately identify actual State Routes. We then determined the following four locations and associated transit agencies that either have already implemented or are in the process of implementing a BRT project within their operational boundaries and that have been recommended for or already received federal funding and are on the SHS in their respective state:

- Roaring Fork Valley, Colorado (Roaring Fork Valley Transit)

- Cleveland, Ohio (Greater Cleveland Regional Transit Authority)

- Eugene-Springfield, Oregon (Lane Transit District)

- Austin, Texas (Capital Metro Transit)

Similarly, appropriate points of contact were subsequently identified, contacted, and questioned by means of phone interviews.

\section{Analysis and Findings}

\section{Similarities and Differences between Transit- and Highway-Based Project Development Procedures}

From Table 1, we observe that both sets of procedural steps begin and end at the same phase, that is, Systems and Regional Planning and Construction, respectively. There is also a high overall level of similarities contained within each procedural step, with instances in which the same individual action occurs in the same procedural step. For example, "Identify \& prioritize local, regional, and statewide transportation objectives" is included in System and Regional Planning for both flowcharts and "Contractor carries out construction activities" is included in Construction for each of the flowcharts. However, there are also instances in which the same individual action occurs in different procedural steps. Table 1 shows (by means of arrows) several examples connecting the same individual action between each set of PDPs. For example, "Identify the transportation problem(s) and project need to address problem(s)" is included in Systems and Regional Planning for 
highway-based projects, while it is included in Alternatives Analysis for transitbased projects (indicated by the top arrow connecting these two steps in Table 1).

There are also Caltrans-specific and FTA-specific individual actions. For example, there are steps within the FTA-based PDP where FTA approval is required to authorize transition of the project sponsor or implementer from the Alternatives Analysis phase to the Preliminary Engineering step and from Preliminary Engineering to the Final Design step.

There are also rules or practices established by usage that govern the order of implementing individual steps. For example, according to the FTA-based PDP, the Alternatives Analysis and resulting selection of the Locally Preferred Alternative (LPA) are conducted immediately after the Systems and Regional Planning phase near the start of its PDP, whereas for the Caltrans-based PDP, the Alternatives Analysis and subsequent LPA selection are conducted later during the Project Approval \& Environmental Document step.

Finally, the two sets of PDPs sometime use the same term that may not be associated with the exact same meaning or interpretation; this can also contribute to delay in the implementation of a BRT project. For example, preliminary engineering is conducted during the Project Approval \& Environmental Document phase of the highway-based PDP, and its activities include the Alternatives Analysis as well as "surveys and mapping, traffic forecasts and modeling, value analysis, hydraulic studies, right-of-way and utilities need/impact assessments, railroad issues, materials/geotechnical information studies, and multimodal alternatives" (Caltrans 2011). For transit-focused projects, the preliminary engineering phase consists of "identification of all environmental impacts and making adequate provision for their mitigation in accordance with NEPA" and the "design of all major or critical project elements to the level that no significant unknown impacts relative to their costs or schedule will result" (Federal Transit Administration 2011).

\section{Project Implementation Delays: General and Site-Specific}

There are two primary criteria that determine which PDPs are followed:

- Whether the BRT project is located along the SHS.

- Whether the agency implementing the BRT project (transit agency, metropolitan planning organization [MPO], transportation authority) has applied and been approved for federal financial support for at least partial funding of its project. 
Each of these criteria may be satisfied or not, producing a total of four possible outcome combinations to consider. The qualitative likelihood of implementation delay for a BRT system for each of these four outcomes is described in Table 2. Clearly, delays are more likely when a BRT project is both on an SHS and receiving federal funding and least likely when a BRT project is neither on an SHS nor receiving federal funding. When a BRT project is not on an SHS, yet it is receiving federal funding, the implementing agency such as the relevant transit agency or MPO has to follow only the FTA set of project development procedures, and process-related delays are not likely. Similarly, when a BRT project is on an SHS but receives no federal funding, the implementing agency has to follow only the State's PDP, and, again, process-related delays are unlikely. However, in the latter case, the implementing agency could require assistance to ensure that it is sufficiently familiar with the State's PDP to preclude further delay.

Table 2. BRT Project Implementation Delay Resulting from Following PDPs

\begin{tabular}{|c|l|l|}
\hline $\begin{array}{c}\text { On State } \\
\text { Highway } \\
\text { System? }\end{array}$ & \multicolumn{2}{|c|}{ Applied/Approved for Federal Financial Support? } \\
\cline { 2 - 3 } & \multicolumn{1}{|c|}{ Yes } & \multicolumn{1}{|c|}{ No } \\
\hline Yes & $\begin{array}{l}\text { Can and sometimes do experience } \\
\text { process-related delays because transit } \\
\text { agency must conform to two project } \\
\text { development processes that have differ- } \\
\text { ences in content and order of steps, and/ } \\
\text { or timing for completion of steps. }\end{array}$ & $\begin{array}{l}\text { Implementing agency has to follow } \\
\text { only State highway-based PDP and } \\
\text { so process-related delays are unlikely. } \\
\text { However, implementing agency could } \\
\text { require assistance to ensure that it is } \\
\text { sufficiently familiar with State's PDP to } \\
\text { preclude further delay. }\end{array}$ \\
\hline \multirow{5}{*}{ No } & $\begin{array}{l}\text { Implementing agency has to conform } \\
\text { only to FTA transit-related PDP. Level } \\
\text { of detail and how streamlined the PDP } \\
\text { depends on whether project is part of } \\
\text { New Starts, Small Starts, or Very Small } \\
\text { Starts Program. Process-related delays are } \\
\text { unlikely. }\end{array}$ & $\begin{array}{l}\text { Transit agencies will still use some } \\
\text { form of generic PDP and likely base } \\
\text { it on known FTA PDP (as opposed to } \\
\text { Caltrans highway-based PDP), yet they } \\
\text { do not have to worry about being com- } \\
\text { pliant with FTA's rules and guidelines. } \\
\text { Delays are unlikely. }\end{array}$ \\
\hline
\end{tabular}

In total, there were 16 site-specific assessments conducted by phone interviews with appropriate points of contact. Four of the 16 BRT projects investigated have experienced implementation delays, while the remaining 12 have not; each is on the SHS in their respective state and has either applied for or already received federal funding: 
- East Bay BRT, San Francisco Bay Area/AC Transit

- VelociRFTA/Roaring Fork Valley Transportation Authority (RFTA), Colorado

- Euclid Avenue BRT/Greater Cleveland Regional Transit Authority (GCRTA)

- Monterey Peninsula BRT/Monterey Salinas Transit (MST) District

\section{Factors Contributing to BRT Project Implementation Delays}

Numerous factors have played an influential role in the type of issues and extent of time delays that were experienced by the four BRT implementing agencies in the context of following both State and federal PDPs for these projects. Such factors include:

- Relationships among organizational and agency stakeholders and the level of coordination among them.

- Specific agency (and its type) with project approval and implementation authority.

- Degree of common language used in the PDPs and potential for multiple interpretation of terms because of potentially differing transit and highway contexts.

- Extent of impact of BRT project on the SHS, e.g., queue lane or traffic signal only; full or partial removal of a travel lane or parking lane.

- Type and level of financial commitment, especially extent of State funding that can serve as an incentive to participate and see the project to a successful conclusion because of such a financial investment.

- Experience and familiarity of state DOT and implementing agency (transit agency or local/regional transportation authority) with each other's culture and way of conducting business.

- Federal view of the State's role, i.e., whether seen as equal partner or just one of the locals.

- Issues and potential implementation delays are more likely to occur in certain PDP steps than others, e.g., early in the PDP, there is less likelihood of delays.

\section{Implementing BRT Projects with No Time Delays}

In the other 12 projects, there were no implementation delays. Four of these projects consist of routes that are both on the SHS and have either applied for or already received federal funding. For two of these four projects, it is important to note that the relevant state DOTs are sufficiently flexible in their project oversight to permit the FTA-based set of PDPs to have priority over their own set of State procedures. For another one of these four projects, it is currently too early in the 
implementation to have experienced delays, according to the project implementation agency. The fourth project has not experienced delays because of current very limited involvement in the project by the state DOT due to resource constraints and uncertainty of continued involvement.

For the 5 of 12 BRT projects that are on the SHS but without federal funding, 1 project is currently not actively moving forward; another is at an extremely early stage of development, having not yet applied for federal funding; another essentially does not have state DOT involvement because it is in mixed-flow traffic, not a bus-only lane. The implementing agency for another project is negotiating with the state DOT over State relinquishment of control over the BRT route, and for the fifth of these 12 projects, which is actively moving forward toward implementation, there is some unfamiliarity with the state DOT's PDP, but this is not an issue contributing to any process-related delay.

For the three remaining BRT projects that are not on the California SHS-all of which are in the San Diego metropolitan area-two are not receiving federal funding and the third, which is receiving federal funding, strictly follows the FTA-based PDP and so is not experiencing any delay thus far.

\section{Summary of Findings}

Table 3 summarizes the findings of the 16 site-specific case studies in terms of which sets of PDPs each implementing agency must adhere to and whether there have been project implementation delays. The table also provides a brief description of each project's capital improvements (where data are available) to understand the potential influence that capital intensity may have on project implementation delay. Capital improvement data were available for 14 of the 16 case study projects. Only 3 of the 14 projects are minor (Monterey Peninsula, Rapid 3, and Escondido Breeze), while the remaining 11 are capital-intensive.

Three of the 4 projects that have experienced implementation delay and that follow both federal and State PDPs are capital-intensive, while 8 of the 10 projects without implementation delay are also capital-intensive. In particular, all four of the projects without implementation delay that follow both federal and State PDPs are capital-intensive. Thus, based on the available data for this limited case study sample, the degree to which capital intensity may contribute to implementation delay, if at all, is uncertain. 


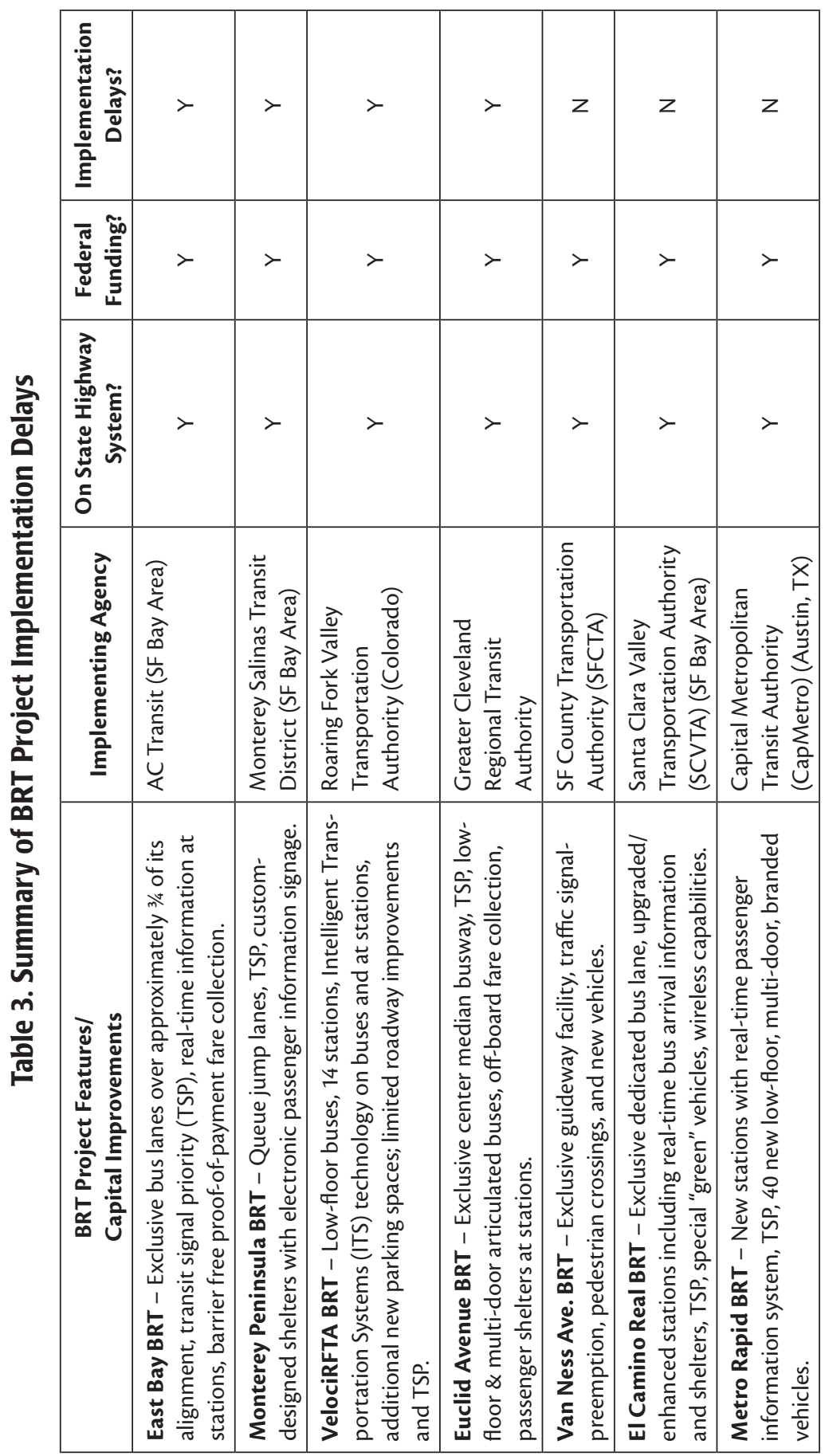




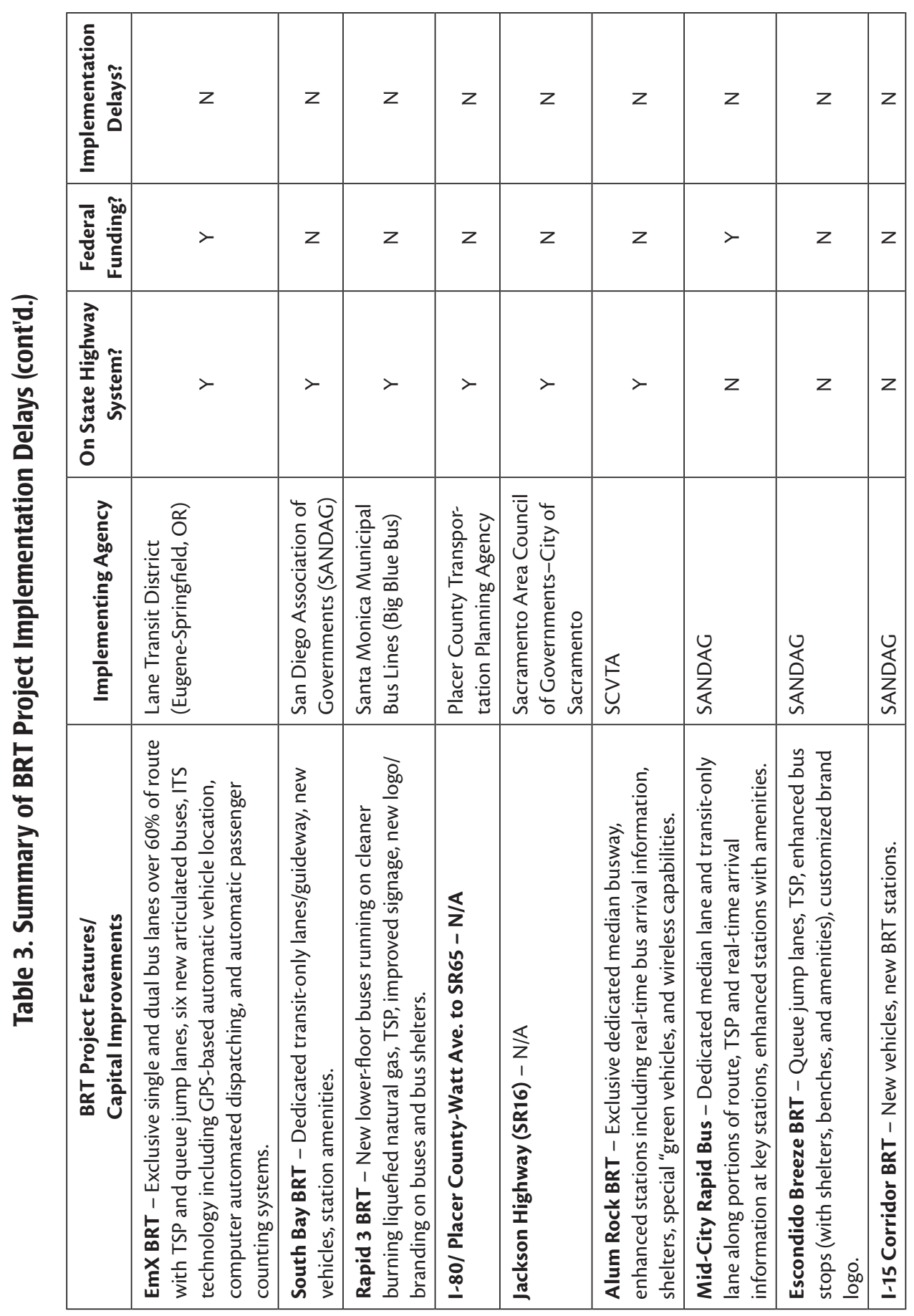




\section{Recommendations}

Based on our investigative case studies of agencies implementing BRT projects, we developed general recommendations that, when converted into practice, can help mitigate the issues and implementation delays associated with having to follow both State and federal PDPs. However, it should still be noted that every project is different, with its own set of jurisdictional, institutional, and operational characteristics, and that a period of adjustment and trial-and-error may be necessary to determine which recommendations work best for each project. The recommendations are as follows:

1. There should be more direct and improved communications among project partners, especially between the relevant state DOT and federal partners (FTA representatives), throughout the course of the project; this may be converted into practice by having direct meetings-teleconference, video conference, or face-to-face-among project partners but especially between the state DOT and FTA. It is important for State officials to understand that the federal perception of the State project role may at times be that the State is "just one of the locals" instead of a co-equal project partner. It is also important to get federal recognition of the existence of and need to sometimes adhere to the State PDPs as well as the federal PDPs and that conflicts can sometimes arise.

2. The implementing agency (local/regional transit agency) needs to be proactive and assume a leadership role in seeking FTA and state DOT guidance to help preclude issues from occurring.

3. Each set of PDPs should be examined at the start of the project with state DOT and FTA representatives to:

a. identify similarities and differences

b. determine where comprises can and cannot be made

c. determine who has priority under what circumstances at what procedural steps and whether one partner is willing to grant priority status to the other partner

d. recognize and resolve differences among terms and language used vis-à-vis the transit vs. highway contexts

e. identify steps in the State and federal PDPs where merging of tasks between them may be allowed as part of a plan to allow more flexibility in carrying them out; this will depend on the unique charac- 
teristics of each individual BRT project and the extent of the impact of each BRT project on the SHS.

This recommendation may be converted into practice by conducting the start of a discussion at the project kick-off meeting on both the state DOT's and FTA's PDPs to follow sub-bullets a. through e. above. This task should continue throughout the project planning, design, and construction phases; a working subgroup of the Project Team could be tasked with this assignment and with submitting follow-up progress reports.

4. Agencies should become aware and take advantage of project-specific opportunities; one way this may be converted into practice is by identifying, if possible, agency staff who have experience and familiarity with the business culture of both the state DOT and the implementing agency. Having someone able to "see both sides" of an issue can help smooth out differences and issues that arise and make forward progress on the project.

\section{Conclusions}

This paper documents an investigation of PDPs for the implementation of BRT systems whose routes are on an SHS and are also part of the federal New Starts Project Planning and Development Program, which brings together two different types of transportation implementation projects: the traditional highway construction project and a public transportation project. The focus is on two sometimes differing PDPs — State and federal-both of which must, at times, be followed. Because of such differences, conflicts can arise and contribute to the use of resources that might not otherwise be used and to project implementation delays. Initially, a comparison of both State and federal PDPs was made to understand the similarities and differences between these two sets of procedures, which was followed by sitespecific assessments of BRT projects that formed the basis of recommendations that, when put into practice, could help mitigate the impact of having to follow multiple sets of PDPs for a single BRT project and to help implement such a project more efficiently with fewer delays.

The recommendations involve working within the framework of existing PDPs used by State and federal agencies- "low hanging fruit" type of recommendations-and initially targeting what is easier to achieve or solve. The recommendations do not involve changes to either set of State or federal procedures, which could be challenging to implement. Modifying only federal procedures could be especially problematic because of the potential need for such procedures to be simultaneously 
more aligned and compatible with each set of individual State procedures, which could be a very difficult logistical task to implement.

Next steps that may be followed in the short-term in the pursuit of reducing BRT project implementation delays are to carry out these recommendations on specific BRT projects and test their effectiveness at reducing the conflicts arising together with associated delays due to the need to adhere to both State and federal PDPs. If these recommendations prove to be less effective than hoped for, then an alternative strategy would be to modify each individual State PDP to be more in line with the federal PDP.

\section{Acknowledgments}

This work was performed under the sponsorship of the State of California Business, Transportation and Housing Agency, Department of Transportation (Caltrans), Division of Research and Innovation (DR\&l). The contents of this paper reflect the views of the author, who is responsible for the facts and the accuracy of the data presented herein. The contents do not necessarily reflect the official views or policies of the State of California. The author thanks Bradley Mizuno of DR\&l for his management of and advice during the project. The author also thanks each member of the Caltrans Project Advisory Panel for their valuable reviews and comments during the project.

\section{References}

Caltrans. 2009. Project Development Procedures Manual. State of California, Department of Transportation, Division of Design.

Caltrans. 2011. How Caltrans builds projects. Caltrans Office of Project Development Procedures.

Diaz, R. B., and Hinebaugh, D. 2009. Characteristics of Bus Rapid Transit for DecisionMaking (CBRT). Federal Transit Administration, FTA-FL-26-7109-2009.1.

Federal Transit Administration. FTA Major Capital Transit Investment Fact SheetNew Starts Project Development. FTA Office of Planning and Environment and Office of Program Management, http://fta.dot.gov/12347_5221.html [accessed December 10, 2011]. 
Federal Transit Administration. 2011. Annual report on New Starts. FTA Office of Planning and Environment and Office of Program Management, http://fta.dot. gov/12304_2618.html [accessed May 15, 2011].

Kittelson \& Associates, Inc., et al. 2007. TCRP Report 118-Bus Rapid Transit practitioner's guide. Transit Cooperative Research Program, Transportation Research Board, Washington, D.C.

Levinson, H. S., et al. 2003. TCRP Report 90-Bus Rapid Transit volume 2: Implementation guidelines. Transit Cooperative Research Program, Transportation Research Board, Washington, D.C.

\section{About the Author}

MARK A. MiLleR (markallan.miller@gmail.com) is a transportation research consultant who retired in 2011 from the California PATH Program at the University of California, Berkeley after 22 years as a Research Specialist. While at PATH, his research centered on developing evaluation frameworks and methodologies and performing impact assessments of ITS technologies in the setting of field tests and site-specific case studies. His work experience was well balanced between quantitative and qualitative investigations covering technical, deployment, societal, and institutional aspects of ITS. Mr. Miller has significant work experience in the areas of transit operations research and policy and behavioral research, including BRT. Between 2003 and 2011, he was also a Visiting Scholar at the Institute of Transportation Studies within the Luskin School of Public Affairs at the University of California, Los Angeles. In addition to conducting his research at UCLA, he gave lectures on ITS. 